\title{
Research of the opportunity of using bran as a building material
}

\author{
Maria Gaydabrus ${ }^{1, *}$, Dias Mussafirov ${ }^{1}$, and Roman Tabakaev ${ }^{1}$ \\ ${ }^{1}$ National Research Tomsk Polytechnic University, 634050 Tomsk, Russia
}

\begin{abstract}
As a result of the functioning of the agro-industrial complex, several million tons of bran that require recycling are annually produced in Russia. At present, there is no resource-efficient way of utilizing bran, which ensures its ecological compatibility and economic efficiency. In this regard, the purpose of the paper is to investigate the possibility of using wheat bran as a building material. The article presents the prerequisites for the construction of low-rise buildings using wheat bran as a building material: an experiment was carried out for the manufacture of bran blocks, and their thermophysical characteristics, maximum crushing strength, and moisture resistance were measured. Building blocks made from bran have a thermal conductivity comparable to the thermal conductivity of wood. The high strength of the bran blocks to squeeze indicates the possibility of their use for the construction of low-rise buildings without any strengthening of their design. However, this blocks exhibit hydrophilic properties, which requires the application of a protective layer. For example, a conventional wood varnish can be use as such a coating.
\end{abstract}

\section{Introduction}

The Russian Federation is one of the leading countries in terms of grain production and export [1]. In 2017, the grain harvest in Russia amounted to a record 136 million tons [2]. However, the technical equipment of Russian grain processing enterprises has a rather low efficiency, not allowing more than $45-65 \%$ of the finished product to be produce from the feedstock [3]. This leads to a huge accumulation of agricultural waste - bran.

In practice, bran is used as a feed additive to animals or poultry, amounting to $15-60 \%$ of the total weight of mixed fodder $[4,5]$. However, this direction is limited by poor palatability and low digestibility by animals [6].

Options are considered for burning bran for energy needs [7, 8]. However, the slagging ability, characteristic for vegetable fuels, leads to low combustion efficiency and quick failure of boiler equipment.

Disposal of bran by burial can lead to severe environmental consequences: a strong and stable crust forms on the surface of the earth, which adversely affects the further use of soil $[5]$.

\footnotetext{
* Corresponding author: 779030742352@mail.com
} 
It is necessary to continue searching for ways of rational utilization of bran. As such a direction, the manufacture of building materials from bran can be considered. Bran is an environmentally friendly raw material, which makes it possible to obtain environmentally friendly natural materials on their basis.

Today, environmental construction is an actual world trend, which refers to the erection of all types of buildings. It arose in the $60 \mathrm{~s}$ of the XVIII century on the example of construction of individual housing and remained imperceptible until the end of the XX century. Sharp interest in the issues of ecological housing construction has emerged in the last decade: the world community realized that human civilization plays a huge role in the destruction of our planet, introducing it into its activity in an unstable state.

Strengthens the ecological construction not only the growth of prices for building materials, but also the high toxicity of many of them. In addition, eco-materials are a renewable resource that exists in many parts of the earth. Nature provides at our disposal many wonderful building materials, such as clay, stones, wood, straw, bark, leaves, reeds, etc.

For example, a straw house [9] is one of the types of eco-building objects, for the erection of which blocks from pressed straw are used. The modern construction of thatched buildings began in the late $19^{\text {th }}$ century in the United States, which is considered the world leader in the construction of houses from biomass materials (over 100,000 houses). These houses have low construction costs, excellent microclimate, strong enough; due to low weight do not require a heavy foundation and lifting gear.

Moreover, such houses have a great ability to heat insulation and carbon dioxide absorption, which increases their interest in large metropolitan areas and contaminated areas.

In this regard, the purpose of the study is to investigate the possibility of using wheat bran as a building material. The article provides the prerequisites for the construction of low-rise buildings using wheat bran as a building material.

\section{Material and methods}

As a research object, we chose wheat bran.

The values of the thermal characteristics of bran (thermal conductivity, heat capacity and thermal diffusivity) are determined on the Discovery Laser Flash DLF-1200 thermal diffusivity analyzer (TA Instruments, USA) in the temperature range 298-423K. For this, the bran was pre-compressed $(\mathrm{P} \approx 200 \mathrm{MPa})$ using a hydraulic press.

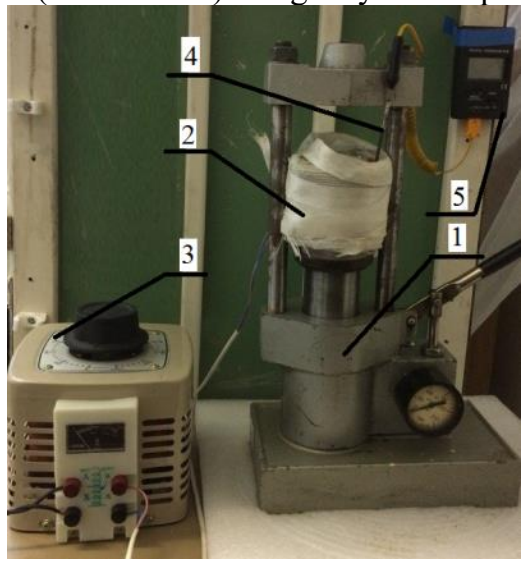

Fig. 1. Laboratory installation for the production of bran blocks: 1 - hydraulic hand press, 2 - indirect heated mold, 3 - auto transformer, 4 - thermal couple (type K), 5 - thermometer. 
For manufacturing building blocks from bran, a manual hydraulic press with a heated mold was used (Fig. 1). A sample of bran (weight is $150 \mathrm{~g}$ ) was poured into a mold and pressed according to recommendations [7] at a pressure of 10-15 $\mathrm{MPa}$ and a temperature of $140^{\circ} \mathrm{C}$ for $10-20$ minutes.

The strength of the blocks produced was determined by loading the blocks with pressure until it destroyed. To carry out these tests, was used a hydraulic press. The maximum pressure at which the block was destroyed was taken as the strength of the block for crushing.

Some of the blocks were previously covered with a protective layer - yacht wood varnish. Then the mass of blocks covered with a protective layer and without it was measured. The blocks were wetted with distilled water for 20 minutes, after which they were wiped dry and weighed.

A change in the shape of the water drop on the surface of the block was also investigated. For this purpose, we used a Levenhuk DTX 500 microscope with a magnification of $30^{x}$.

\section{Results and discussion}

On the Fig. 2 shows the results of determining the thermal characteristics of the studied bran. It is seen that as the temperature increases, the thermal conductivity and heat capacity of bran increases, and the thermal diffusivity decreases. The thermal conductivity of the bran block is comparable to the thermal conductivity of most types of wood $(\lambda=0.1$ $0.2 \mathrm{~W} /(\mathrm{m} \times \mathrm{K})[10-12])$, which indicates the possibility of using blocks in places with low temperatures (down to $-40^{\circ} \mathrm{C}$ ) in winter. In this case, the thickness of the walls of the blocks should have the same value as the wood wall recommended for a particular region.

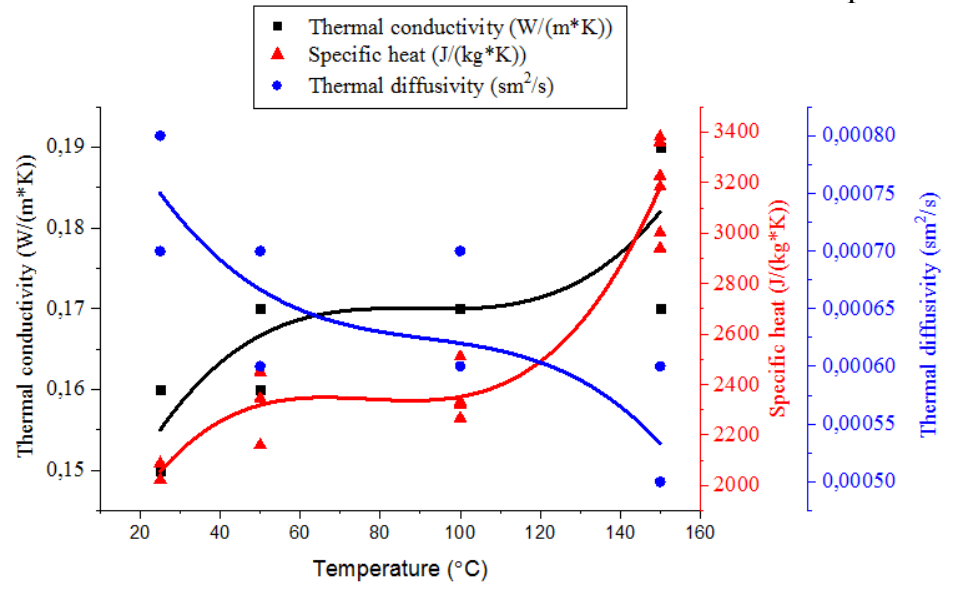

Fig. 2. Measured values of specific heat, thermal conductivity and thermal diffusivity of bran.

The strength of the blocks produced was determined by loading the blocks with pressure until it destroyed. To carry out these tests, was used a hydraulic press. The maximum pressure at which the block was destroyed was taken as the strength of the block for crushing.

According to the recommendations [7] blocks of bran are made (Fig. 3). The strength tests showed that the block was destroyed at a pressure of $35.5 \mathrm{MPa}$. The strength of the block was about $1112.6 \mathrm{~kg} / \mathrm{m}^{3}$. This indicates that blocks of bran are suitable for the construction of low-rise buildings without any strengthening of their construction. 


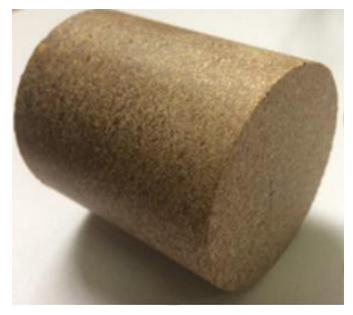

Fig. 3. Measured values of specific heat, thermal conductivity and thermal diffusivity of bran.

Water resistance tests showed that when exposed to water, blocks that are not protected by the water repellent layer gradually swell, lose their shape and eventually break down. The application of a protective layer, for example, of yacht lacquer, intended for wood processing, allows ensuring water resistance of the blocks.

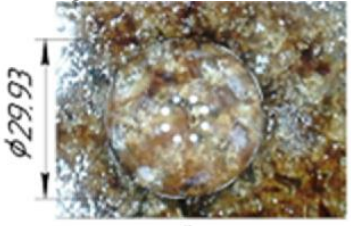

0
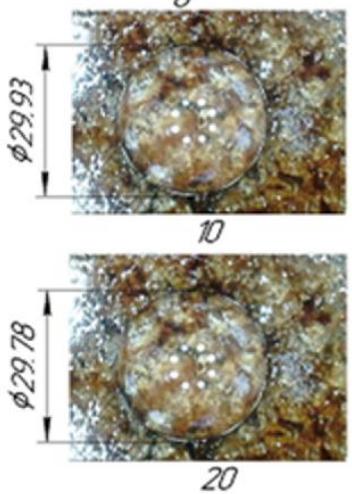

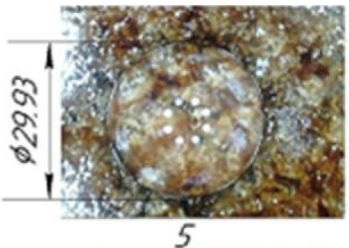

5
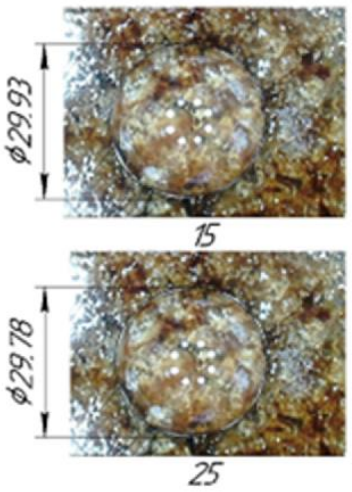

Fig. 4. The shape of a drop of water on the surface of the block of bran, pre-treated with varnish, over a period of time (an increase of $30^{\mathrm{x}}$ ).

As can be seen from Fig. 4, the shape of the drop does not change with time, which indicates the hydrophobic properties of the block. After 20 minutes, the size of the drop decreases, which can be explained by the gradual evaporation of water from the surface of the block.

\section{Conclusions}

Building blocks made from bran have a thermal conductivity comparable to the thermal conductivity of wood. Given the widespread prevalence of wood as a material for the construction of low-rise buildings, it can be assumed that bran due to similar thermal characteristics will be able to compete with it in this segment.

The high strength of the bran blocks to squeeze indicates the possibility of their use for the construction of low-rise buildings without any strengthening of their design.

Blocks from bran exhibit hydrophilic properties, which require the application of a protective coating. For example, a conventional wood varnish can be used as such a coating. 
The research is funded from Grant Council of the President of the Russian Federation. The experimental calculations are carried out at Tomsk Polytechnic University within the framework of Tomsk Polytechnic University Competitiveness Enhancement Program grant.

\section{References}

1. I. G. Generalov, S. A. Suslov, Bulletin NGII 40 (9), 3 (2014)

2. M. A. Nikolaeva, L. V. Kartashova, Food Industry 3, 77 (2018)

3. A. I. Altukhov, Vestnik of Kursk State Agricultural Academy 5, 2 (2015) [in Russian]

4. E. B. Etuk, A. V. Ifeduba, U. E. Okata, I. Chiaka, C. Ifeanyi, N. J. Okeudo, B. O. Esonu, A. B. I. Udedibie, J. C. Moreki, J Anim Sci Adv. 2, 510 (2012)

5. S. V. Antimonov, R. F. Sagitov, S. Yu. Solovykh, Izvestia vuzov.Pishevaya tekhnologia 2-3, 61 (2008) [in Russian]

6. V. D. Kaminsky, A. Y. Karunsky, M. B. Babich, Hranenie i pererabotka zerna [Storage and processing of grain] 5, 42 (2000) [in Russian]

7. M. Gaydabrus, I. Razov, R. Tabakaev, V. Lebedev, MATEC Web Conf. 110 (2017)

8. M. Yu. Chernetskiy, A. A. Dekterev, A. Burdukov, Journal of Siberian Federal University.Engineering \& Technologies 6, 625 (2013)

9. M. Myhrman, S. O. MacDonald, Build it with Bales: A Step-by-step Guide to Strawbale Construction (Chelsea Green Publishing Company, London, 1997)

10. A. U. Franchuk, Tables of heat engineering indicators of building materials (Research Institute of Building Physics, Moscow, 1969) [in Russian]

11. A. P. Babichev, N. A. Babushkina, A. M. Bratkovsky, Physical quantities.Reference book (Energoatomizdat, Moscow, 1991) [in Russian]

12. V. Blazy, Handbook of the designer.Building physics (Technosphere, Moscow, 2004) [in Russian] 